\title{
DYNAMIC IMAGE ANALYSIS TO DETERMINE GRANULE SIZE AND SHAPE, FOR SELECTED HIGH SHEAR GRANULATION PROCESS PARAMETERS
}

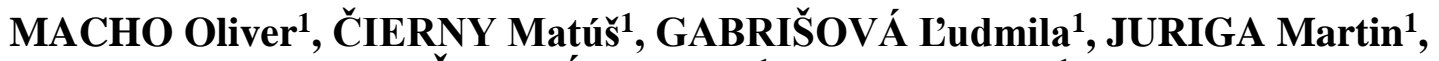 \\ RUŽINSKÝ Radovan ${ }^{1}$, PECIAR Peter ${ }^{1}$ \\ ${ }^{1}$ Slovak University of Technology in Bratislava, Faculty of Mechanical Engineering, Institute of Process \\ Engineering, Námestie Slobody 17, 812 31Bratislava, Slovakia, e-mail: oliver.macho@stuba.sk
}

\begin{abstract}
The aim of this study was to investigate the usage of Dynamic Image Analysis for determination of size, shape and distribution of granules of microcrystalline cellulose, created by high shear granulation. A series of experiments was carried out to analyse the effect of process parameters on a created granule morphology. The amount of the granulation liquid and speed of the impeller have a significant effect on the median size granule value, the sphericity, the granule distribution width, but also on the granulation process yield.
\end{abstract}

KEYWORDS: High shear granulation, Dynamic Image Analysis, Microcrystalline cellulose

\section{Introduction}

Wet granulation is the process by which, with the use of a granulation liquid, a large number of small particles of a primary powder mixture can be transferred to a small amount of large particles. These modified particles have different properties in comparison with the original material. Granulation is an important process, widely used and applied for the aggregation of powder clusters in various industries including mineral processing, agricultural products, detergents, pharmaceuticals, food and chemicals [1]. High shear granulation is one of the usual operations for the modification of powder materials properties in the pharmaceutical industry. With high shear granulation, the impeller impacts the powder mixture and ensures movement of the powder layers. During this process a binder solution is distributed and the powder mixture is compacted and densified. The impeller speed significantly effects the size [2], structure [3], shape [4] and strength [5] of the created granules. The particle size and shape significantly affect the flow properties, which can be presented as the angle of internal friction [6], [7], [8] or as the angle of repose [9]. The amount of granulation liquid is another key parameter for high shear granulation. Adding liquid binder to the powder secures the formation of nuclei. The nuclei size distribution is a function of wetting kinetics and thermodynamics [10]. The amount of liquid added and wet massing time are statistically more significant parameters than the water addition rate [11]. The aim of this study was to examine the effect of two key parameters in high shear granulation on the size and shape of the created granules. Dynamic image analysis (DIA) was used to analyze the shape and the size of the granules. DIA is technique for characterization of granules in movement by digitalizing photos of each granule and storing them in an image file. The images are used to calculate morphological parameters based on the known size and location of the pixels in each image. A series of experiments was carried out at different impeller speeds and with different amounts of the granulation liquid. 


\section{Experimental part}

\subsection{Experimental material}

Microcrystalline cellulose (Avicel PH101, FMC Biopolymer) was used as the experimental powder material, which was obtained from the IMCD group. This material is commonly used in the pharmaceutical industry as a binder, lubricant or a solvent in the production of solid dosage forms [12]. Avicel average particle size is $d_{\text {mean }}=46 \mu \mathrm{m}$, bulk density $\rho_{\mathrm{B}}=333 \mathrm{~kg} / \mathrm{m}^{3}$, true density $\rho_{\mathrm{T}}=1580 \mathrm{~kg} / \mathrm{m}^{3}$. Granulation liquid was $2 \%$ aqueous solution of polyvinylpyrrolidone powder (Biochemica) prepared by a magnetic stirrer at $38^{\circ} \mathrm{C}$.

\subsection{Granulation}

The high shear granulation of the experimental material was implemented in a vertical granulator of our own production [13]. The granulator is equipped in the vertical orientation with a three-blade bottom-driven impeller and a five-blade horizontal chopper. The material batch consists of 0.51 of Avicel. The chopper speed was set to a constant $1000 \mathrm{rpm}$. The impeller speed varied from 300 to $700 \mathrm{rpm}$. The granulation liquid was sprayed into the granulation chamber through a nozzle using a membrane dosing pump, with a flow rate of 22.5 $\mathrm{ml} / \mathrm{min}$. Wetting time was changed in relation to individual experiments, which were repeated three times. Wet massing time was $2 \mathrm{~min}$. After granulation, the created granules were weighed and dried in an oven for 24 hours at $60^{\circ} \mathrm{C}$. The dried granules were separated by 0.4 and $3 \mathrm{~mm}$ sieves. Particles below $0.4 \mathrm{~mm}$ were classified as fine, particles within the range of $0.4-3 \mathrm{~mm}$ as product and particles above $3 \mathrm{~mm}$ were classified as coarse. The individual fractions were weighed again in order to determine process yield in relation to the impeller speed and the amount of granulation liquid used. The absolute humidity of the granules was determined as the ratio of the weight of the dry granulate relative to the weight of the wet granulate. For convenience, this parameter was expressed as a percentage.

\subsection{Dynamic image analysis}

DIA was performed using PartAn 3D [14]. Unlike 2D devices, PartAn 3D measures the third dimension of the particle: thickness. Dynamic image analysis has found its application in granule research [15], in milling processes [16], [17], in particles analysis [18] or analysis of micro tablets [19]. The dried granules in the $0.4-3 \mathrm{~mm}$ range characterized as product were analyzed to find their size and shape and the distribution curve width. The granules were characterized volumetrically. The area equivalent diameter $D_{a}$ taken as the equivalent size, was obtained from a 3D image of the particles calculated according to (1).

$$
D_{a}=\sqrt{\frac{4 A}{\pi}}
$$

where $A$ is the area of the examined particles. The particle shape was expressed by sphericity (2).

$$
\phi=\frac{D_{a}}{D_{p}}
$$

where $D_{p}$ is the equivalent perimeter diameter of the particle calculated according to (3).

$$
D_{p}=\frac{P}{\pi}
$$


where $P$ is the perimeter of the examined particles. The distribution width of the created granules was characterized by span (4).

$$
\operatorname{span}=\frac{d_{90}-d_{10}}{d_{50}}
$$

where the equation takes into account the tenth $\left(d_{10}\right)$, fiftieth $\left(d_{50}\right)$, and ninetieth percentile $\left(d_{90}\right)$. The lower the span value, the more monodisperse the fractional composition is.

\section{Results and discussion}

\subsection{Granule size distribution}

Increasing the content of the granulation liquid used in high shear granulation resulted in an increase in the median size of granules. Up to an absolute humidity of $50 \%$ (approximately 500 $\mathrm{s}$ of wetting time) the increase of granule size was approximately linear, but when this value was exceeded, there was a rapid increase in the median granule size. A similar trend is found in [20], but in this work the authors used only distilled water as the granulation liquid. Fig. 1 shows the dependences between $d_{50}$ and wetting time for three different impeller speeds. The graph shows that a higher impeller speed resulted in an increase in shear deformation resulting in more intense granular breakage. It can be seen in the graph that the median size of granules decreased in proportion to the increasing impeller speed. At the impeller speed of $300 \mathrm{rpm}$ and a wetting time of $590 \mathrm{~s}$ the larger granules were created with $d_{50}=1.975 \pm 0.049 \mathrm{~mm}$, while at impeller speed of $700 \mathrm{rpm}$ and a wetting time of $640 \mathrm{~s} d_{50}$ was only $1.02 \pm 0.014 \mathrm{~mm}$.

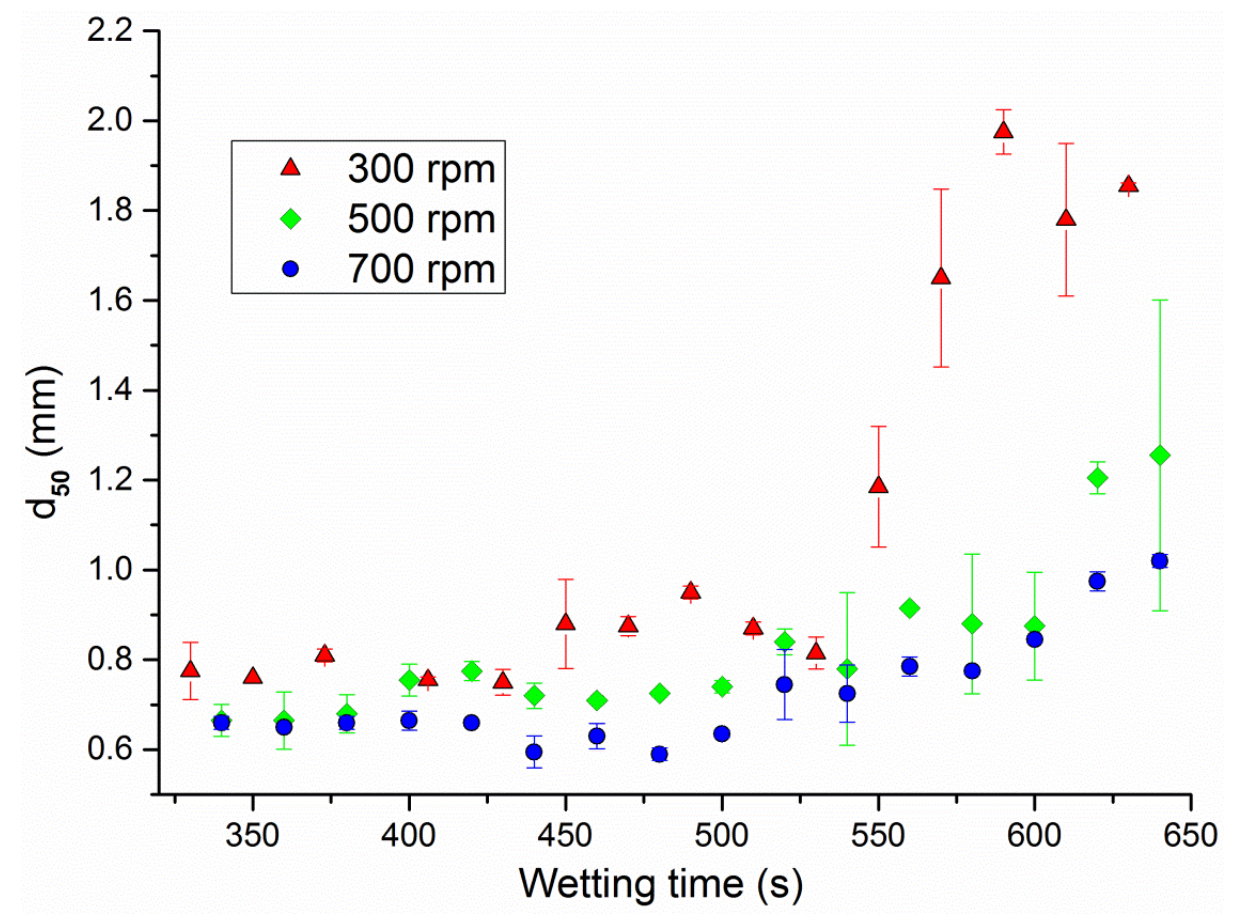

Fig. 1 Dependences of the median size of the granules on wetting time, for different impeller speeds.

Fig. 2 shows the distribution cumulative curve of granule size distribution at the impeller speed of $300 \mathrm{rpm}$ for different wetting times. The graph shows that increasing the amount of the granulation liquid used for production of granules resulted in significant differences in the repeatability of measurements. These differences are shown in the graph in the form of standard deviations. The most significant deviations were recorded at the impeller speed of $300 \mathrm{rpm}$ and the wetting times of 550, 570 and $610 \mathrm{~s}$. At the impeller speed of $300 \mathrm{rpm}$, the most significant deviation was at the wetting time of $640 \mathrm{~s}$, at which the median value $d_{50}=1.255 \pm 0.346 \mathrm{~mm}$. 
Significant particle deformation at $700 \mathrm{rpm}$ resulted in good repeatability of experiments coupled with minimal deviations throughout the wetting time range.

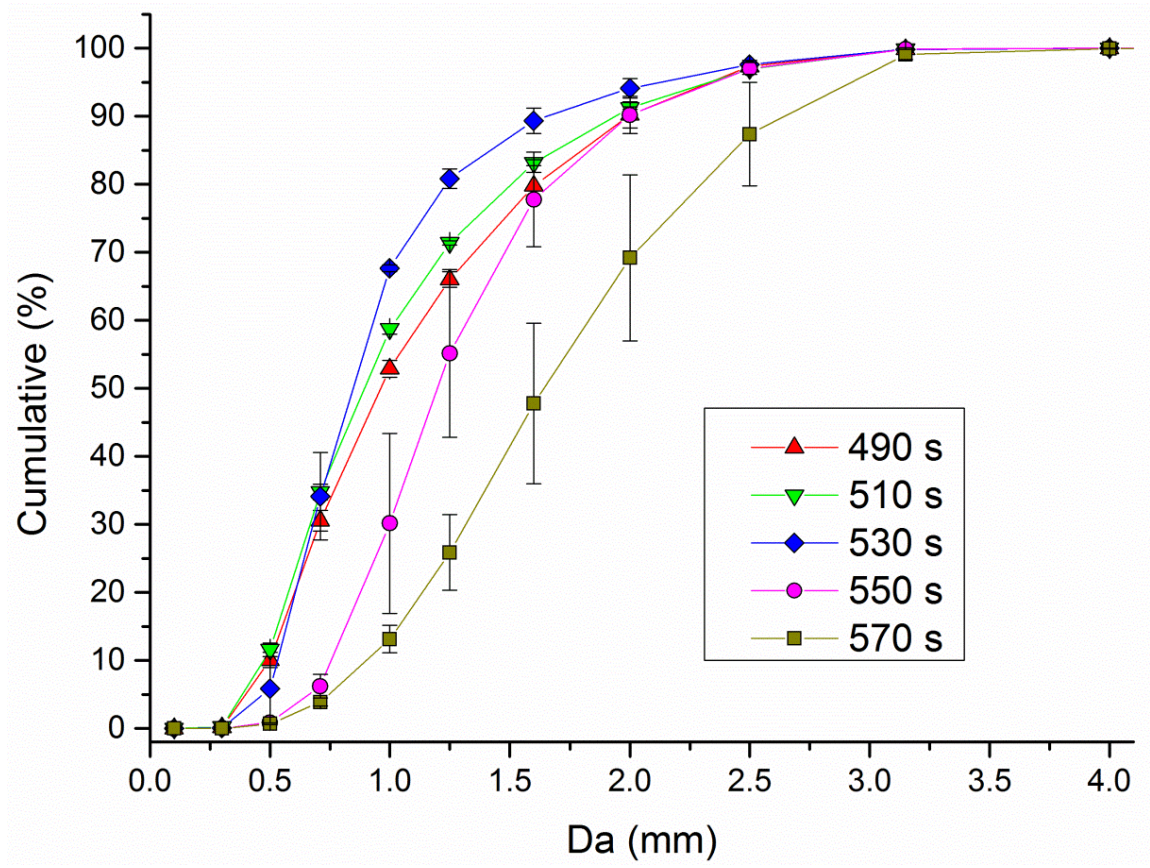

Fig. 2 The cumulative size distribution of the granules produced

for different wetting times at the impeller speed of $300 \mathrm{rpm}$.

The effect of the impeller speed was reflected in the shape of the granules formed. The sphericity value in Fig.3 corresponds to the average sphericity of all granules from each batch. The graph shows that at the lowest impeller speed $(300 \mathrm{rpm})$ granules with a sphericity $>0.9$ were produced only at a wetting time of $470 \mathrm{~s}$ (absolute humidity $50 \%$ ). Granules with sphericity of 1 would have a perfect ball shape. At the impeller speeds of 500 and $700 \mathrm{rpm}$, a granular sphericity value $>0.9$ was achieved at a wetting time of $420 \mathrm{~s}$ (absolute humidity 47 $\%)$. This finding suggests that granules with higher average sphericity were produced at higher impeller speeds. The graph also shows that at a lower amount of granulation liquid used, the measurements were accompanied by more significant deviations in the sphericity values. At a higher granulation liquid amount, there were no longer any significant differences between the different impeller speeds. Based on these findings, granules with a higher mean sphericity can be formed at a higher granulation liquid amount.

When analysing the distribution width of the formed granules, in addition to experiments at the impeller speed of $300 \mathrm{rpm}$, no significant dependences were found. Fig.4 shows graphical dependences of the distribution width of the formed granules as a function of wetting time. At $300 \mathrm{rpm}$ the wetting time had a steady linear trend until $510 \mathrm{~s}$ (absolute humidity $52 \%$ ) then began to decrease, indicating that the granules formed had a monodisperse fractional composition. The lowest value of span was at the impeller speed of $300 \mathrm{rpm}=0.904 \pm 0.019$. At higher impeller speeds, the span value initially increased with increasing wetting time and then reached a minimum at a wetting time of $500 \mathrm{~s}$ (absolute humidity $\pm 50 \%$ ). At the impeller speed of $700 \mathrm{rpm}$, the lowest span value was $0.795 \pm 0.002$. After exceeding an absolute humidity of $51 \%$, the width of distribution began to increase again as the granulation liquid amount increased. 


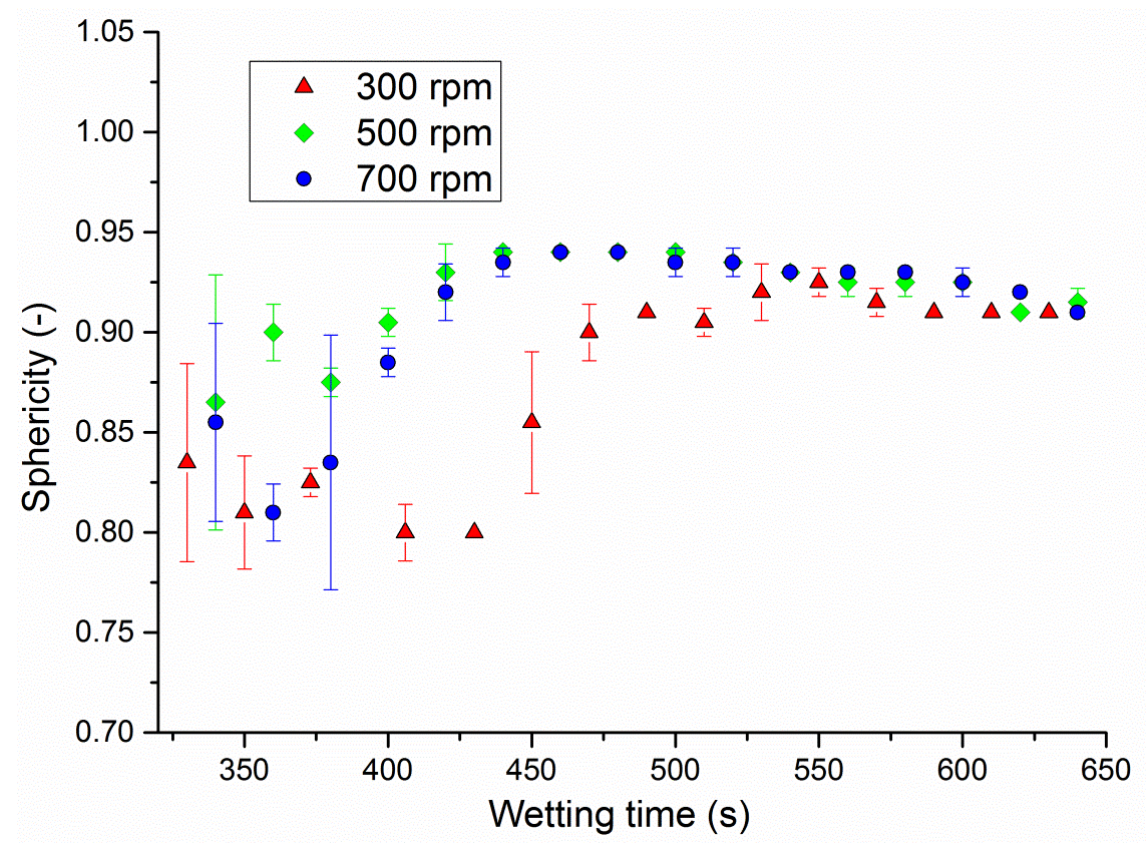

Fig. 3 Mean sphericity distribution in dependences on wetting

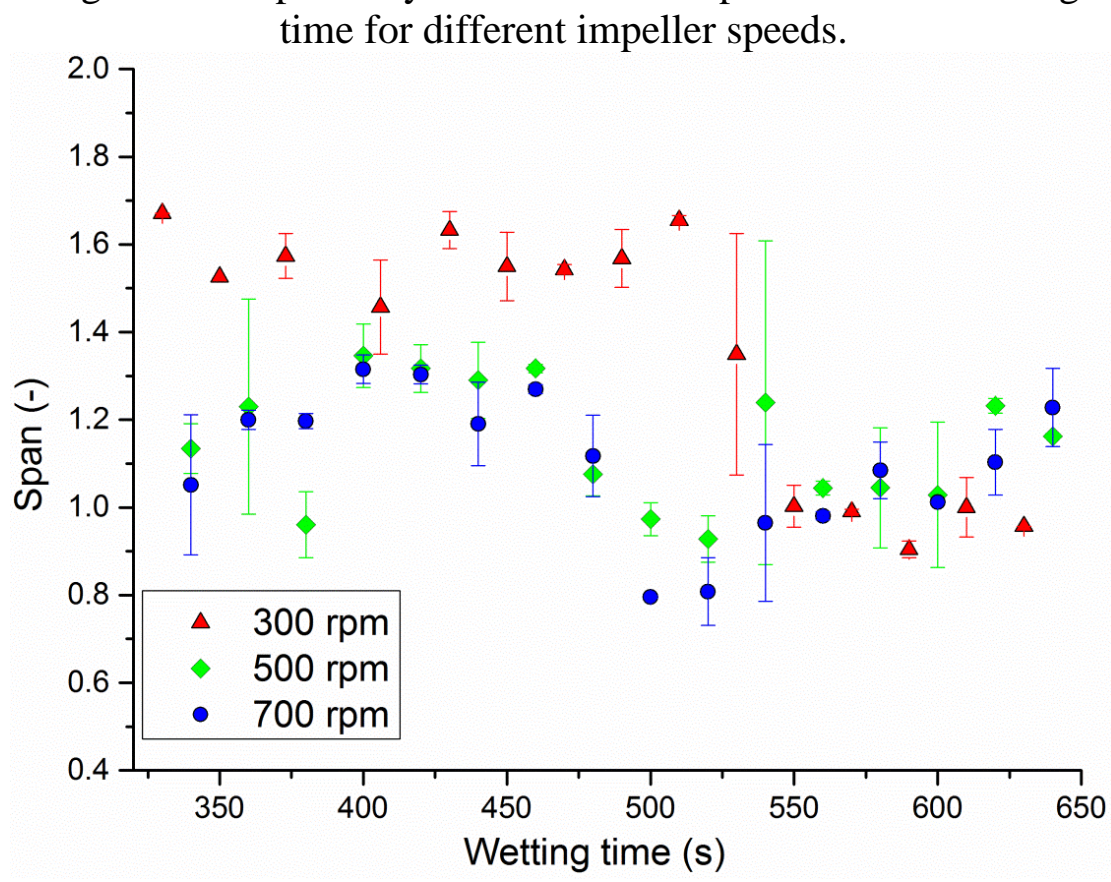

Fig. 4 The distribution width of the granules produced depending on the wetting time for different impeller speeds.

Based on the weights of the individual fractions, the yield of the product was determined as the weight of the granulate characterised as the product (granules $0.4-3 \mathrm{~mm}$ ), divided by the total weight of all the grades. Fig.5 shows a graphical relationship between process yield and wetting time for all impeller speeds. The graph shows that the process yield increases linearly with the granulation liquid amount, up to the value when increasing wetting time produces no changes. At the impeller speed of $300 \mathrm{rpm}$, this occurred at $52 \%$ absolute humidity, at 500 and $700 \mathrm{rpm}$ at an absolute humidity of $49 \%$. At $300 \mathrm{rpm}, 31.25 \%$ of the experiments had a yield of more than $80 \%$. At 500 and $700 \mathrm{rpm}$ the yield was more than $80 \%$ in $50 \%$ of all experiments. Significant deviations in the experiments were rarely observed. As the granulation liquid amount increased, the proportion of fine particles decreased. As the impeller speed increased, the proportion of coarse particles below $3 \mathrm{~mm}$ decreased (at $700 \mathrm{rpm}<1 \mathrm{~g}$ for all 
experiments). Similar results, however, with different intervals of particle size can be found in [21], [22], [23].

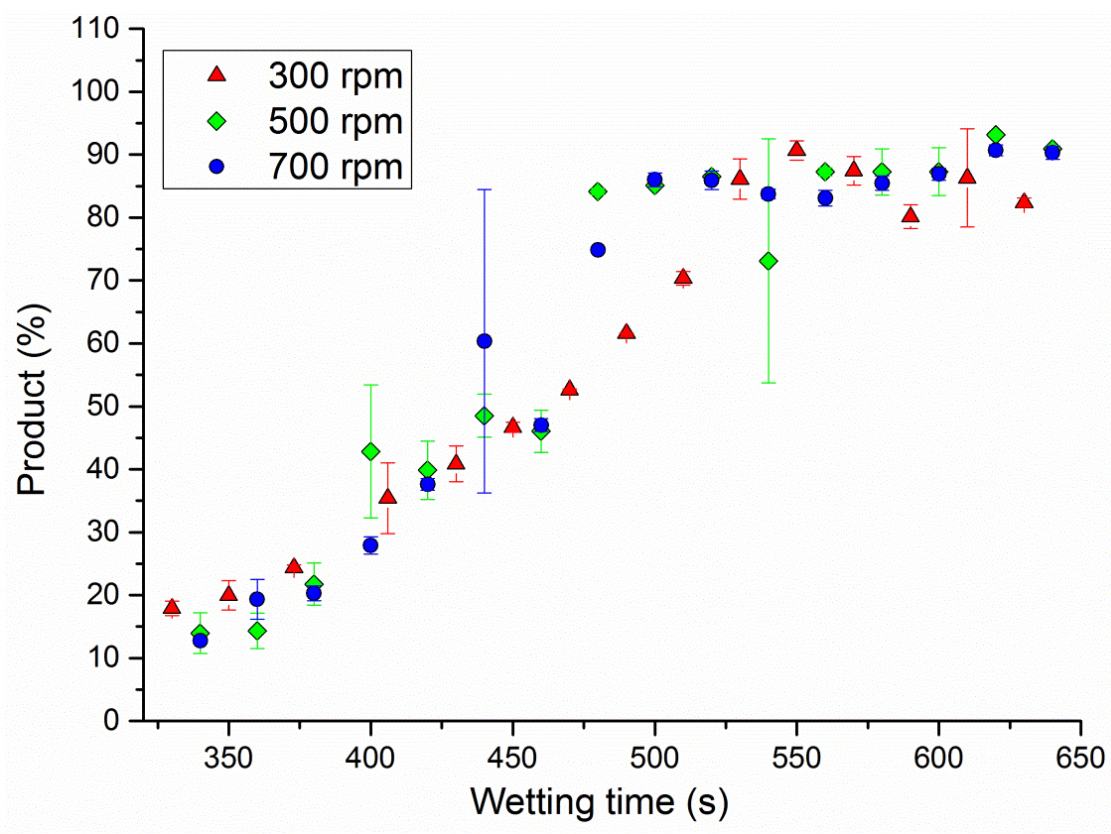

Fig.5 Yield of process in dependences on wetting time for different impeller speeds.

\section{CONCLUSION}

The investigated process parameters of the impeller speed and varying amounts of liquid delivered have a significant effect on the morphological properties and the distribution of the granules formed. As the granulation liquid amount increased, so did the median particle size, which was influenced by the impeller speed. Higher impeller speeds resulted in smaller granules due to the dynamic action of the impeller, with the same amount of granulation liquid used. Longer wetting times resulted in the formation of granules with a high mean sphericity. The effect of the impeller on mean sphericity was more significant with granules formed up to \pm 50 $\%$ absolute humidity. The most monodisperse granules were formed at a higher impeller speed and an absolute humidity value of $\pm 50 \%$. As the granulation liquid amount increased, the linear yield of the process increased until the state when additional granulation liquid did not affect it. At higher impeller speeds, $50 \%$ of all experiments had a product yield of more than $80 \%$. At the impeller speed of $300 \mathrm{rpm}$, a process yield of $80 \%$ was achieved at up to $52 \%$ absolute humidity. As the granulation liquid amount increased, the proportion of fine particles $(<0.4 \mathrm{~mm})$ decreased. As the impeller speed increased, the proportion of coarse particles $(>3$ $\mathrm{mm}$ ) decreased. The 3D Dynamic Image Analysis method has proved to be a reliable tool for analyzing the distribution size and shape of the granules created by the high shear granulation process.

\section{ACKNOWLEDGEMENT}

This work was supported by the Slovak Research and Development Agency under contract No. APVV-18-0348. The authors would like to thank Microtrac GmbH and IMCD Group for their cooperation in the research. The authors wish to acknowledge the Ministry of Education, Science, Research and Sport of the Slovak Republic for the financial support of this research by grant KEGA 016STU-4/2019. 


\section{List of symbols}

\begin{tabular}{|c|c|c|c|}
\hline$A$ & - & Area of projected image & $\left(\mathrm{mm}^{2}\right)$ \\
\hline$d_{10}$ & - & $10 \%$ of particles under reported particle size & $(\mathrm{mm})$ \\
\hline$d_{50}$ & - & $50 \%$ of particles under reported particle size & $(\mathrm{mm})$ \\
\hline$d_{90}$ & - & $90 \%$ of particles under reported particle size & $(\mathrm{mm})$ \\
\hline$D_{a}$ & - & Area equivalent diameter & $(\mathrm{mm})$ \\
\hline$d_{\text {mean }}$ & - & Mean diameter of primary powder & $(\mu \mathrm{m})$ \\
\hline$D_{p}$ & - & Equivalent perimeter diameter & $(\mathrm{mm})$ \\
\hline$P$ & - & Perimeter of projected image & $(\mathrm{mm})$ \\
\hline$\phi$ & - & Sphericity & $(-)$ \\
\hline$\rho_{B}$ & - & Bulk density & $\left(\mathrm{kg} / \mathrm{m}^{3}\right)$ \\
\hline$\rho_{T}$ & - & True density & $\left(\mathrm{kg} / \mathrm{m}^{3}\right)$ \\
\hline
\end{tabular}

\section{REFERENCES}

[1] Mahdi, F. M., Mehrabi, M., Hassanpour, A., Muller, F. L. "On the formation of core-shell granules in batch high shear granulators at two scales", Powder Technology 356, pp. 253 - 262, 2019. DOI: 10.1016/j.powtec.2019.08.019

[2] Oulahna, D., Cordier, F., Galet, L., Dodds, J. A. "Wet granulation: The effect of shear on granule properties", Powder Technology 130, pp. 238 - 246, 2003. DOI: 10.1016/S00325910(02)00272-3

[3] Rahmanian, N., Ghadiri, M., Jia, X., Stepanek, F. "Characterisation of granule structure and strength made in a high shear granulator", Powder Technology 192, pp. $184-194$, 2009. DOI: $10.1016 /$ j.powtec.2008.12.016

[4] Mangwandi, C., Adams, M. J., Hounslow, M. J., Salman, A.D. "Effect of impeller speed on mechanical and dissolution properties of high-shear granules", Chemical Engineering Journal 164, pp.305 - 315, 2010. DOI: 10.1016/j.cej.2010.05.039

[5] Rahmanian, N., Naji, A., Ghadiri, M. "Effects of process parameters on granules properties produced in a high shear granulator", Chemical Engineering Research and Design 89, pp. 512 - 518, 2011. DOI: 10.1016/j.cherd.2010.10.021

[6] Gužela, Š., Juriga, M., Fekete, R. "Vplyv vel'kosti častíc partikulárnej látky na uhol vnútorného trenia", Strojnícky časopis - Journal of Mechanical Engineering 60 (2), pp. 105 - 120, 2009. ISSN 0039-2472

[7] Trpělková, Ž., Hurychová, H., Ondrejček, P., Svěrák, T., Šklubalová, Z. "Predicting the Angle of Internal Friction from Simple Dynamic Consolidation Using Lactose Grades as Model", Journal of Pharmaceutical Innovation, Article in Press, 2019. DOI: $10.1007 / \mathrm{s} 12247-019-09387-3$

[8] Eckert, M. "Determination of the rheological properties of powdered materials", Transfer 2017 - 18th internal scientific conference, pp. 1 - 8, 2017. ISBN 978-80-8075-787-8.

[9] Hurychová, H., Kuentz, M., Šklubalová, Z. Fractal "Aspects of Static and Dynamic Flow Properties of Pharmaceutical Excipients", Journal of Pharmaceutical Innovation 13, pp. 15 - 26, 2018. DOI: $10.1007 / \mathrm{s} 12247-017-9302-0$ 
[10] Iveson, M. S., Litster, J. D., Hapgood, K., Ennis, B. J. "Nucleation, growth and breakage phenomena in agitated wet granulation processes: A review ", Powder Technology 117, pp. 3 - 39, 2001. DOI: 10.1016/S0032-5910(01)00313-8

[11] Van den Ban, S., Goodwin, D. J. "The Impact of Granule Density on Tabletting and Pharmaceutical Product Performance", Pharmaceutical Research 34 (5), pp. 1002 - 1011, 2017. DOI: $10.1007 / \mathrm{s} 11095-017-2115-5$

[12] Peciar, P., Eckert, M., Fekete, R., Hrnčiar, V. "Analysis of Pharmaceutical Excipient MCC Avicel PH102 Using Compaction Equations", Strojnícky časopis - Journal of Mechanical Engineering 66 (1), pp. 65 - 82, 2016. DOI: 10.1515/scjme-2016-0012

[13] Macho, O., Kabát, J., Gabrišová, L., Peciar, P., Juriga, M., Fekete, R., Galbavá, P., Blaško, J., Peciar, M. "Dimensionless criteria as a tool for creation of a model for predicting the size of granules in high-shear granulation", Particulate Science and Technology, Article in Press, 2019. DOI: 10.1080/02726351.2018.1548531

[14] Macho, O., Peciar, P., Peciar, M., Svěrák, T. "Distribution Characteristics and Compressibility of Agglomerates as a Reflection of Granulation Parameters", Scientific Proceedings 23, Faculty of Mechanical Engineering, STU in Bratislava, pp. 37 - 42, 2015. DOI: $10.1515 / \mathrm{stu}-2015-0007$

[15] Wilms, A., Knop, K., Kleinebudde, P. "Combination of a rotating tube sample divider and dynamic image analysis for continuous on-line determination of granule size distribution", International Journal of Pharmaceutics: X 1, pp. 1 - 7, 2019. DOI: 10.1016/j.ijpx.2019.100029

[16] Ulusoy, U. "Quantifying of particle shape differences of differently milled barite using a novel technique: Dynamic image analysis", Materialia 8, 2019. DOI: 10.1016/j.mtla.2019.100434

[17] Ulusoy, U., Yekeler, M. "Dynamic image analysis of calcite particles created by different mills", International Journal of Mineral Processing 133, pp. 83 - 90, 2014. DOI: 10.1016/j.minpro.2014.10.006

[18] Bamdini, V., Biondi, G., Cascone, E., Di Filippo, G. "Dynamic image analysis of Etna Sand in one-dimensional compression", Measurement 104, pp. 336 - 346, 2017. DOI: 10.1016/j.measurement.2016.07.050

[19] Czajkowska, M., Sznitowska, M., Kleinebudde, P. "Determination of coating thickness of minitablets and pellets by dynamic image analysis", International Journal of Pharmaceutics 495 (1), pp. 347 - 353, 2015. DOI: 10.1016/j.ijpharm.2015.08.102

[20] Shi, L., Feng, Y., Changquan, C. S. "Roles of Granule Size in Over-Granulation During High Shear Wet Granulation", Journal of Pharmaceutical Science 99 (8), pp. 3322 - 3325, 2010. DOI: $10.1002 / j p s .22118$

[21] Chitu, T. M., Oulahna, D., Hemati, M. "Rheology, granule growth and granule strength: Application to the wet granulation of lactose-MCC mixtures", Powder Technology 208 (2), pp. 441 - 453, 2011. DOI: 10.1016/j.powtec.2010.08.041

[22] Benali, M., Gerbaud, V., Hemati, M. "Effect of operating conditions and physicochemical properties on the wet granulation kinetics in high shear mixer", Powder Technology 190 (1 - 2), pp. 160 - 169, 2009. DOI: 10.1016/j.powtec.2008.04.082

[23] Chitu, T. M., Oulahna, D., Hemati, M. "Wet granulation in laboratory scale high shear mixers: Effect of binder properties", Powder Technology 206 (1-2), pp. 25 - 33, 2011. DOI: $10.1016 /$ j.powtec.2010.07.012 